\title{
Angiographic Findings in Refractory Delayed Cerebral Ischemia
}

\section{Achados angiográficos na isquemia cerebral tardia refratária}

\author{
Nicolás González ${ }^{1 \oplus}$ Alvaro Ruiz $^{2}$ Jorge Mura ${ }^{2}$ \\ ${ }^{1}$ Department of Neurosurgery, Hospital Regional Rancagua, \\ Rancagua, Chile \\ 2 Department of Neurosurgery, Institute of Neurosurgery Asenjo, \\ Santiago, Chile

\begin{abstract}
Address for correspondence Nicolás González, MD, Department of Neurosurgery, Hospital Regional Rancagua, Av. Libertador Bernardo O’Higgins 3065, Rancagua, Chile

(e-mail: nicolasgonzalez28@gmail.com).
\end{abstract}

Arq Bras Neurocir 2019;38:157-165.

\begin{abstract}
Keywords

- subarachnoid hemorrhage

- intracranial vasospasm

- brain ischemia

- angioplasty

\section{Resumo}

Palavras-chave

- hemorragia subaracnoidea

- vasoespasmo intracraniano

- isquemia cerebral

- angioplastia

Background Delayed cerebral ischemia (DCl) follows a refractory course in a subgroup of patients with aneurysmal subarachnoid hemorrhage (SAH), leading to diffuse ischemic injury. The role of angiographic vasospasm (AV) is unknown. Our goal is to study the angiographic alterations and the clinical profile of refractory DCl patients. Methods Retrospective study of patients with SAH who presented with DCI treated with medical and endovascular therapy, with a refractory evolution, defined as multiple ischemic infarction and brain death.

Results Out of a cohort of 336 patients, 7 (2\%) developed refractory DCl. The median age of the patients was $48(38-60)$ years old. Five patients had ruptured anterior communicating artery (ACoA) aneurysms. Four patients were treated with coil embolization, and three with microsurgical clipping. Angiographic vasospasm was classified as severe in 5 cases. Compromise of bilateral circulation was detected in six patients. Distal circulation vasospasm occurred in five cases. Slow circulatory transit times were observed in three patients.

Conclusion Angiographic findings such as bilateral circulatory compromise and distal vasospasm were frequent alterations. Further studies are required to establish the association of these findings with the clinical outcomes.

Introdução A isquemia cerebral tardia (ICT) pode seguir um curso refratário em um subgrupo de pacientes com hemorragia subaracnoidea aneurismática (HSA), levando a uma lesão isquêmica difusa. O papel do vasoespasmo angiográfico (VA) ainda é desconhecido. Nosso objetivo é avaliar as alterações angiográficas e o perfil clínico dos pacientes com ICT refratária.

Métodos Estudo retrospectivo de pacientes com HSA que apresentaram ICT tratados com terapia médica e endovascular, com evolução refratária, definida como infarto isquêmico múltiplo e morte cerebral.
\end{abstract}

(1) Nicolás González's ORCID is https://orcid.org/0000-0003-33518714.

received

December 29, 2018

accepted

April 17, 2019
DOI https://doi.org/

10.1055/s-0039-1692124. ISSN 0103-5355.
Copyright $(2019$ by Thieme Revinter

Publicações Ltda, Rio de Janeiro, Brazil
License terms

(c) $(1) \$$ 
Resultados A partir de uma coorte de 336 pacientes, 7 (2\%) desenvolveram ICT refratária. A mediana de idade foi de 48 (38-60) anos. Cinco pacientes tiveram ruptura de aneurisma da artéria comunicante anterior (ACoA). Quatro pacientes foram tratados com coiling e três com clipagem. O VA foi classificado como grave em cinco casos. Detectou-se acometimento da circulação bilateral em seis pacientes. A circulação distal do vasoespasmo aconteceu em cinco casos. Observou-se tempo de trânsito circulatório lento em três pacientes.

Conclusão Os achados angiográficos, como o acometimento circulatório bilateral e o vasoespasmo distal, foram alterações frequentes. Estudos adicionais serão necessários para confirmar as associações entre os achados angiográficos e os resultados clínicos.

\section{Introduction}

Delayed cerebral ischemia (DCI) is an important cause of neurological morbidity in aneurysmal subarachnoid hemorrhage (SAH). The role of angiographic vasospasm (AV) and its contribution to brain injury in this group of patients is controversial.

Angiographic vasospasm is commonly reported in up to $70 \%$ of SAH cases, and it is known that only $50 \%$ develop neurological deterioration. ${ }^{1}$ Clinical presentation of DCI is heterogeneous, in terms of timing of presentation, clinical manifestations, location of spasms in the vasculature, ${ }^{2}$ severity of vessel stenosis, ${ }^{3}$ and response to treatment. Severe AV is associated with severe ischemia and infarction, but hypoperfusion is also reported in areas without macrovascular vasospasm on computed tomography (CT) perfusion studies. ${ }^{4,5}$

Spreading cortical ischemia, microthrombosis, microcirculatory constriction, and genetic polymorphisms ${ }^{6}$ are other mechanisms that could explain why patients without significant angiographic vasospasm develop cerebral infarction. ${ }^{7,8}$ Which one of these factors is related to a higher risk of stroke is currently not well understood. The study of angiographic findings from patients with refractory delayed cerebral ischemia might lead to insights into the relationship between AV and brain ischemic injury

We report a series of 7 patients with severe DCI and AV, refractory to full medical and endovascular therapy, that ultimately led to brain death. Our objective is to describe the angiographic alterations in this group of patients with severe DCI.

\section{Methods}

This is a retrospective study of patients with aneurysmal SAH, treated with microsurgery or endovascular therapy, during a 3-year period (2014-2016) at Institute of Neurosurgery Asenjo, Santiago, Chile. Inclusion criteria were: diagnosis of DCI according to the current definitions, ${ }^{9}$ and absence of medical (i.e., fever, hydroelectrolytic imbalance, and infection) and of other neurological causes of deterioration (hydrocephalus, seizure). Angiographic vasospasm was established by means of digital subtraction angiography (DSA). Refractory DCI was defined as multiple ischemic infarctions leading to diffuse brain injury in spite of full medical therapy, translating into a hypodense brain parenchyma on $\mathrm{CT}$.

Clinical charts, neuroimaging studies, endovascular and surgical protocols were reviewed. The modified Fisher scale $^{10}$ and World Federation of Neurosurgical Societies (WFNS) scale ${ }^{11}$ were used to grade SAHs. The surgical techniques included cisternal cleansing therapy ${ }^{12}$ and lamina terminalis ${ }^{13}$ fenestration. Hydrocephalus was treated with the installation of an external ventricular drain (EVD).

Oral nimodipine was indicated for all patients on admission. ${ }^{14}$ Delayed cerebral ischemia monitoring included serial clinical examination and transcranial Doppler (TCD) imaging. ${ }^{15}$ Mainstay therapy included fluid resuscitation and induced hypertension, according to the current guidelines. ${ }^{16,17}$ Hypervolemia and hemodilution were not indicated. Computed tomography angiography (CTA) was indicated when clinical deterioration persisted after first tier medical therapy. If AV was diagnosed, DSA was performed by an experienced neuroradiologist, and the severity of the AV was classified as mild, moderate, or severe, according to vessel stenosis $(0-33 \%, 34-66 \%$, and $>67 \%$ decrease in arterial diameter, respectively). Additional angiographic evaluation included slowing of circulatory times after contrast injection, and distal circulation (minor caliber cortical branches) compromise. Method of endovascular therapy (balloon or pharmacological angioplasty) was decided by the endovascular specialist. Nimodipine was used as pharmacological agent for intra-arterial use. Patients with intracranial pressure (ICP) monitoring with an ICP $>20 \mathrm{mmHg}$ were treated with first (deep sedation, drainage of cerebrospinal fluid $[\mathrm{CSF}]$ ), second (hypertonic saline, moderate hyperventilation), and third tier therapies (therapeutic hypothermia, decompressive craniectomy).

\section{Results}

During the study period, a total of 336 patients with SAH were treated at our institution. Seven patients developed refractory DCI (2\%).

The median age of the patients was 48 (38-60) years old. There were five female and two male patients. The characteristics of the patients are resumed in -Table 1. All of the 
Table 1 Patient data

\begin{tabular}{|l|l|l|l|l|l|l|l|}
\hline Patient & Age & Gender & $\begin{array}{l}\text { Medical } \\
\text { History }\end{array}$ & Fisher scale & WFNS scale & Aneurysm & Treatment \\
\hline 1 & 43 & F & HT & IV & 3 & ACoA & Coils \\
\hline 2 & 48 & F & CHD & IV & 2 & ACoA & Clip \\
\hline 3 & 58 & F & HT & IV & 2 & Opht & Clip \\
\hline 4 & 43 & M & CKD, HT & IV & 4 & ACoA & Coils \\
\hline 5 & 38 & F & HT & IV & 2 & Opht & Clip \\
\hline 6 & 60 & F & HT & IV & 2 & ACoA & Coils \\
\hline 7 & 49 & M & ARF & IV & 4 & ACoA & Coils \\
\hline
\end{tabular}

Abbreviations: ACoA, anterior communicating artery; ARF, acute renal failure; CHD, coronary heart disease; CKD, chronic kidney disease; F, female, HT, arterial hypertension; M, male, Opht, Ophthalmic artery; WFNS, World Federation of Neurosurgical Societies.

patients had anterior circulation aneurysms; five were ruptured anterior communicating artery (ACoA) aneurysms (see - Figs. 1, 2, 3, 4 for clinical examples), and 2 were ruptured paraclinoid aneurysms. Four patients were treated with endovascular coiling, and three with surgical clipping.

Two patients had aneurysm rebleeding prior to exclusion. The median time to aneurysm treatment was 1 day (range: 0-8 days). Two patients developed hydrocephalus, requiring external ventricular drainage.

The most frequent clinical manifestation of DCI was consciousness impairment (six patients). Only one patient presented with a new focal neurological deficit (aphasia and hemiparesis).

All patients were treated with endovascular angioplasty. Median time from aneurysm bleeding to angioplasty was 8 days (range: 4-8 days). Median number of angioplasties per patient was 1 (range: $1-2$ ). Three patients were treated with mixed balloon and pharmacological angioplasty, and four with pharmacological angioplasty only. Improvement of vessel stenosis was reported on all of the procedures (-Figs. 2 and $\mathbf{3}$ ).

Angiographic findings are resumed on - Table 2. DSA revealed early vasospasm (occurring in the 1 st 72 hours after bleeding) in 2 patients. Angiographic vasospasm was reported in all patients, and vessel stenosis was classified as follows: severe ( $>67 \%$ stenosis) vasospasm in 5 patients, moderate (34-66\%) in 1 patient, and mild $(<33 \%)$ in 1 patient. Compromise of bilateral anterior circulation was detected in six patients. One patient with a left paraclinoid aneurysm presented with focal angiographic vasospasm of the left anterior circulation (anterior cerebral and middle cerebral artery). Posterior circulation (vertebrobasilar) compromise was reported in one patient ( - Fig. 4). Distal vasospasm of cortical branches was reported in five patients. Slow circulatory times were observed in three patients.

\section{Case 1}

-Fig. 1A: A 43-year-old female presented with thunderclap headache. WFNS scale was graded as 3. A CT of the brain revealed a diffuse SAH (modified Fisher scale IV) and hydrocephalus. An EVD was installed.
-Fig. 1B: DSA confirmed a ruptured ACoA aneurysm, bilateral unruptured middle cerebral artery (MCA) aneurysms, and moderate left A1 vasospasm. Endovascular coil embolization was performed the day after the bleeding.

-Fig. 1C: At 9 days postprocedure, the patient developed consciousness impairment. DSA reported severe anterior circulation and moderate posterior circulation vasospasm. Endovascular treatment was indicated with bilateral internal carotid artery (ICA) and proximal MCA balloon angioplasty.

-Fig. 1D: After initial improvement, the patient deteriorated with multiple ischemic infarcts. Refractory intracranial hypertension developed and in spite of intensive care treatment. Brain death was established 11 days after the rupture of the aneurysm. A CT scan revealed a diffuse ischemic injury.

\section{Case 2}

-Fig. 2A: A 48-year-old male was evaluated at our institution for thunderclap headache. Subarachnoid hemorrhage was observed on CT. DSA revealed an ACoA aneurysm that was treated with surgical clipping.

-Fig. 2B: DSA right ICA artery injection reveals normal vessel caliber at admission.

-Fig. 2C: Seven days after the rupture of the aneurysm, the patient developed aphasia and hemiparesis. DSA revealed severe vasospasm of the ICA, of the A1 and of the M1, and moderate MCA distal vasospasm. The rest of the study confirmed bilateral compromise with slow transit times.

-Fig. 2D: Postangioplasty DSA. Bilateral ICA and M1 balloon angioplasty with intra-arterial nimodipine instillation was performed with marked improvement of vessel stenosis.

\section{Case 3}

-Fig. 3A: A 43-year-old male with a history of renal failure presented with WFNS 4, modified Fisher IV SAH, a left frontobasal intraparenchymal hematoma, and hydrocephalus. An EVD was installed. 

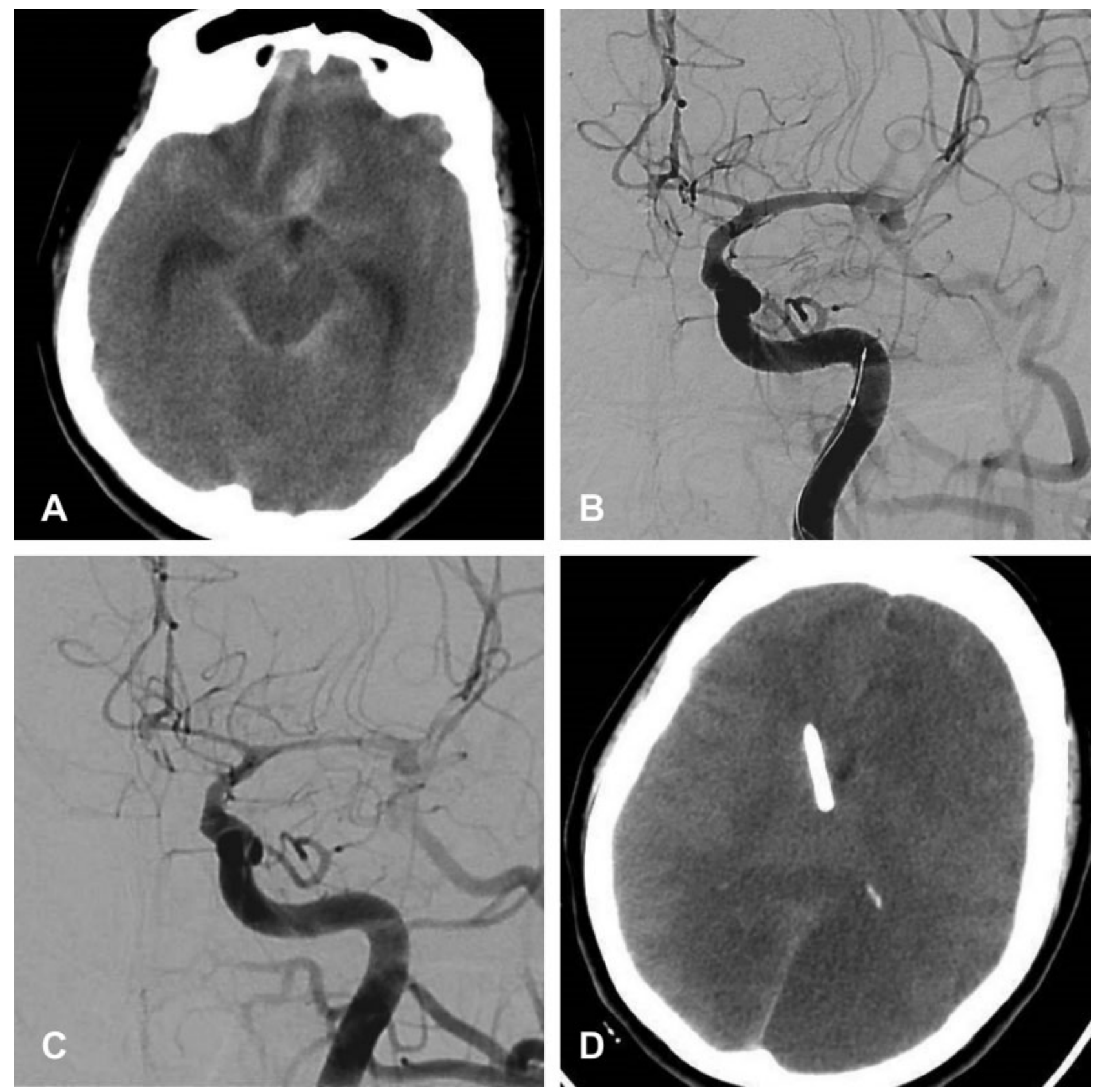

Fig. 1 Case 1. Ruptured AcoA aneurysm with hydrocephalus. Refractory DCI with severe vasospasm of anterior circulation. See text for description.

-Fig. 3B: DSA revealed a ruptured ACoA aneurysm that was treated with coil embolization.

- Fig. 3C: Serial TCD monitoring revealed increased MCA velocities. DSA informed bilateral supraclinoid ICA, M1 segment and pericallosal arteries vasospasm.

-Fig. 3D: Balloon and pharmacological angioplasty were performed 8 days after the initial bleeding. Additionally, two pharmacological angioplasties were indicated for persistent vasospasm. The patient deteriorated and multiple infarcts were observed on CT, with signs of intracranial hypertension. An ICP monitor was installed, and therapeutic hypothermia was started. The patient had an unfavorable evolution and brain death was established 12 days after the rupture of the aneurysm.

\section{Case 4}

-Fig. 4A: A 49-year-old male with a history of alcohol abuse was found by relatives with consciousness impairment. Initial laboratory tests informed acute renal failure. A CT of the brain revealed a modified Fisher IV SAH with an associated frontal interhemispheric hematoma.

-Fig. 4A 4B, 4C: When the renal compromise improved, a DSA was performed, revealing a ruptured ACoA aneurysm with severe anterior and posterior circulation vasospasm. Coil embolization and pharmacological angioplasty were performed. Serial CT imaging revealed hypodensities in multiple arterial territories. Brain death was confirmed 10 days after the initial bleeding. 

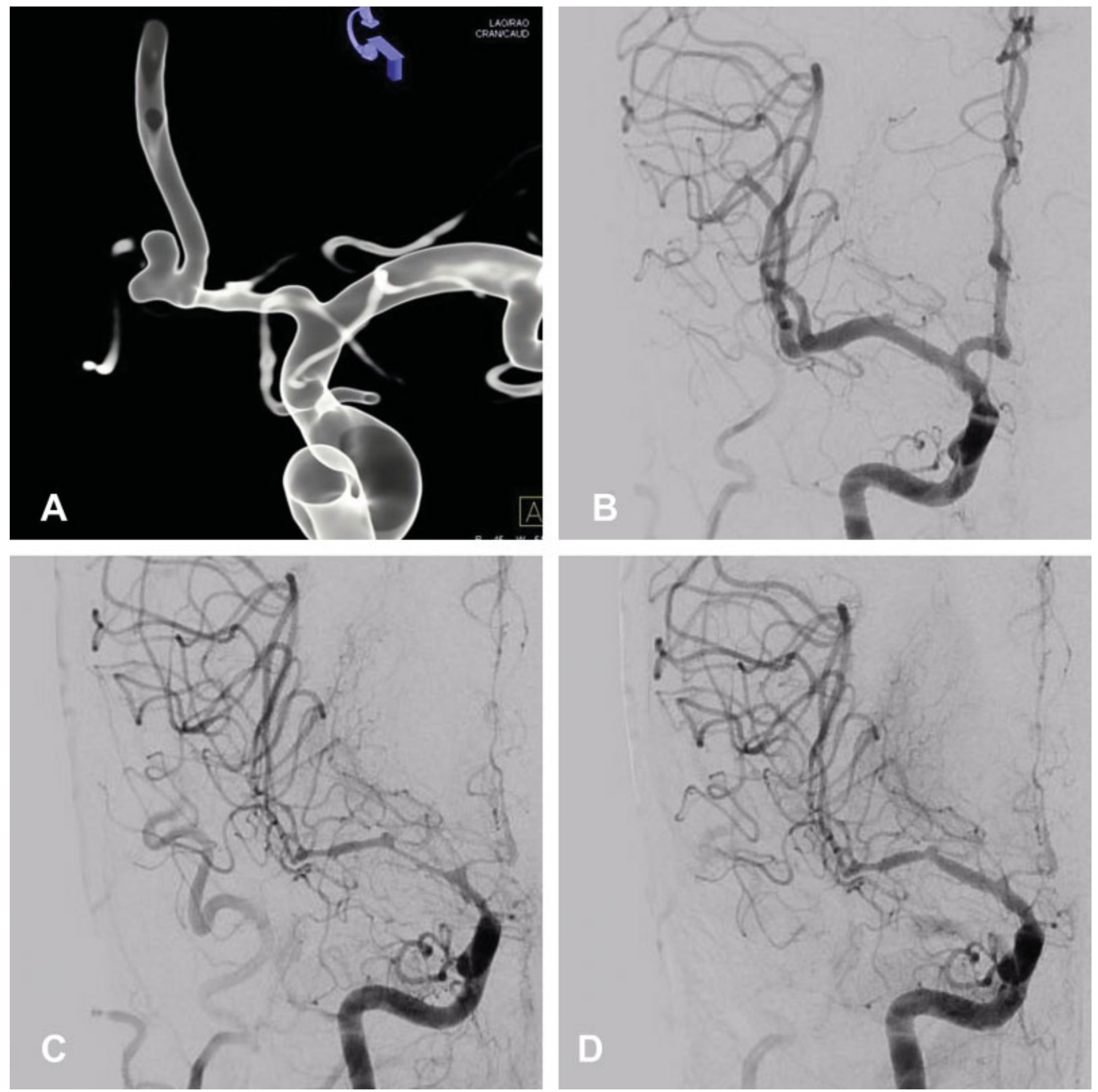

Fig. 2 Case 2. Ruptured AcoA aneurysm. Severe vasospasm of anterior circulation treated with balloon angioplasty. See text for description.

\section{Discussion}

It is known that AV occurs in up to $70 \%$ of the patients with $\mathrm{SAH}$, and that only $30 \%$ of these patients develop DCI that is related to a poor neurological outcome. ${ }^{9}$ The relationship between AV and cerebral infarction is not well-established. ${ }^{18}$

Infarction may develop in territories without significant $\mathrm{AV}$, most likely in watershed areas. ${ }^{19}$ Severe $\mathrm{AV}$, on the other side, is a well-known predictor of cerebral infarction, ${ }^{20}$ and is correlated with perfusion deficits on CT perfusion studies. ${ }^{18}$

In our series, 7 (2\%) out of 336 patients developed this catastrophic complication of SAH. Digital subtraction angiography exams revealed severe vasospasm in five out of seven patients; two were classified as moderate and mild. As such, intracranial vasospasm must be understood as a dy- namic event, and even patients with mild or moderate vessel stenosis reported on the initial DSA may develop DCI with a refractory evolution. Bilateral compromise of the anterior circulation was observed in six patients, indicating a diffuse macrovascular compromise. Distal circulation compromise and slow transit times were frequent findings. A hypothesis could be that these angiographic findings may be red flags of circulatory hemodynamic failure, but we cannot prove this with the design of our study. It is not the goal of the present study to establish causality between this angiographic phenomena and DCI. We can say, however, that the angiographic findings in our cohort of patients with refractory DCI were dynamic, and not restricted only to vessel stenosis. Ultraearly $\mathrm{AV}$, for example, has been associated with refractory $\mathrm{DCI}$ in other studies. ${ }^{21-23} \mathrm{~A}$ common misconception is to 

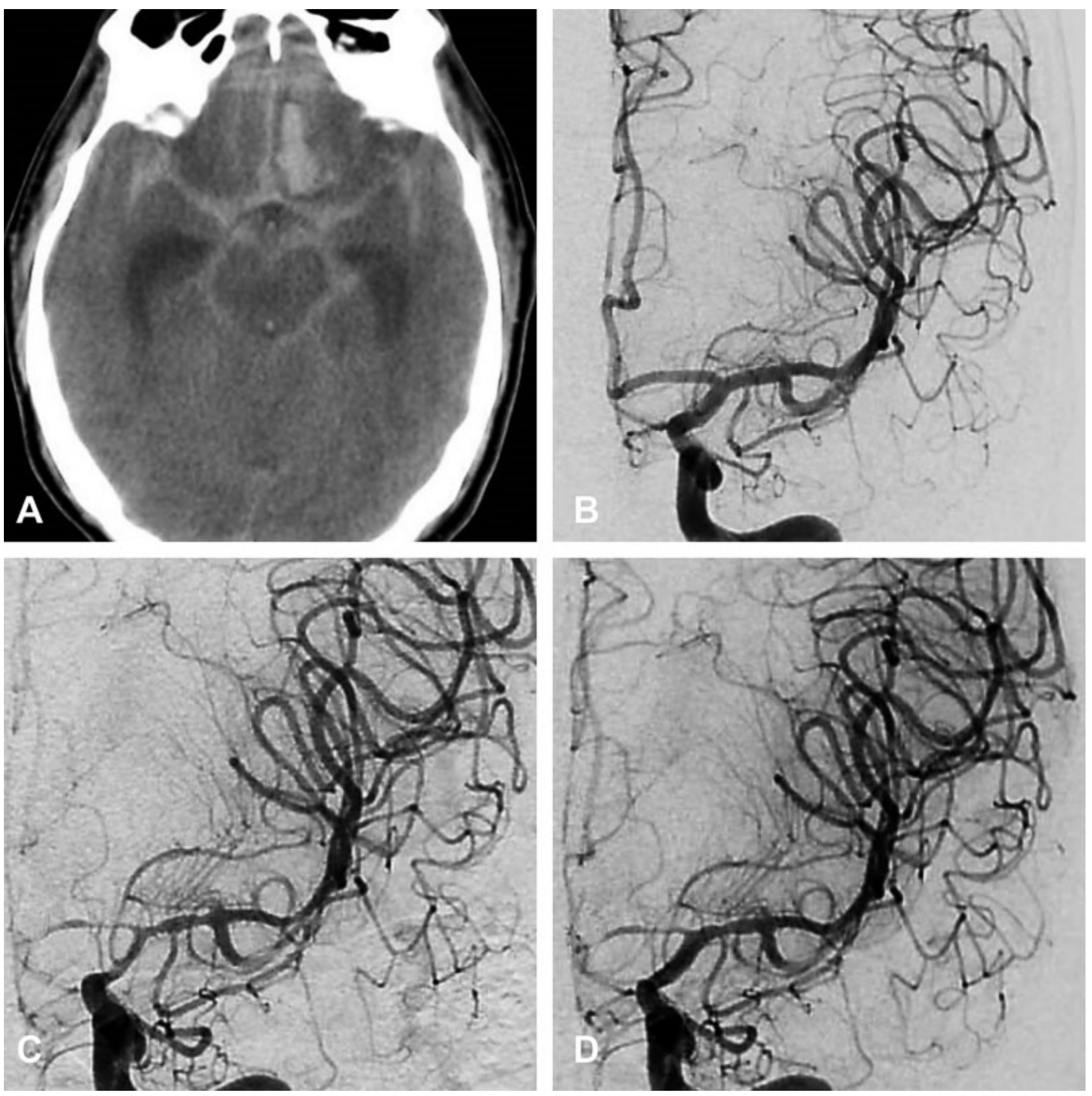

Fig. 3 Case 3. Ruptured AcoA aneurysm with left frontobasal hematoma. Persistent vasospasm after balloon angioplasty. See text for description.

confuse "mild vasospasm severity" in the angiography report as a predictor of "mild" evolution with no risk of brain injury.

Anterior communicating artery aneurysms were the most frequent in our cohort of patients; most of them (80\%) were treated with coil embolization. Injury to hypothalamic structures after bleeding or/and ischemic injury may be a factor associated with a refractory evolution. Microsurgical blood clot removal ${ }^{12}$ in this region may be beneficial in order to avoid irritation of hypothalamic perforators, but further studies are needed to confirm this hypothesis.

The relationship between the location of the aneurysm and DCI was studied by Abla et al. ${ }^{24}$ The authors found that ruptured pericallosal aneurysms were associated with a low clot burden, but with a higher risk of DCI in comparison with other locations.

The most frequent clinical manifestation of DCI was consciousness impairment, a finding that is common in SAH patients in the intensive care unit (ICU), which may also be explained by other medical factors (fever, infections, metabolic disturbances, among others).

Endovascular therapy for symptomatic DCI was indicated for all patients, usually on the most critical period (between the $4^{\text {th }}$ and $8^{\text {th }}$ days). Intra-arterial vasodilator therapy and balloon angioplasty are treatment modalities well-described in the literature, ${ }^{25-27}$ but angiographic improvement is not always associated with clinical improvement, with up to $69 \%$ of reported postprocedural ischemia. ${ }^{28}$ Other mechanisms 

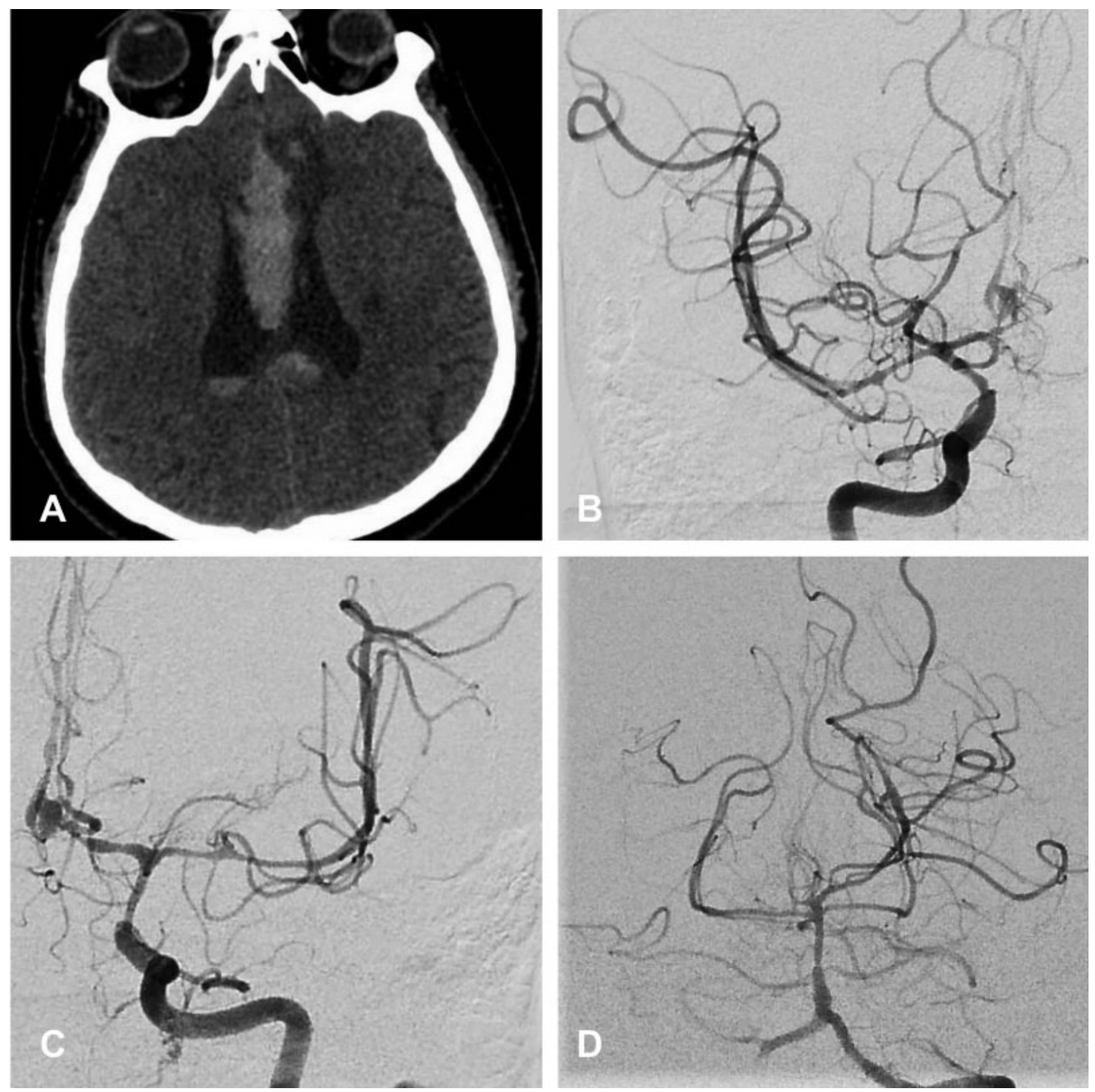

Fig. 4 Case 4. Ruptured AcoA aneurysm with intraventricular hemorrage. Bilateral vasospasm of anterior and posterior circulation. See text for description.

for ischemia are described in this subgroup of patients, such as spreading cortical ischemia, microcirculatory constriction, and microthrombosis. ${ }^{1}$ Angiographic improvement after angioplasty must not be considered an endpoint to decide the withdrawal of hemodynamic intensive care therapy, as improvement of intracranial vessel stenosis was reported in all of our patients after the procedure.

No patient in our series was treated with decompressive craniectomy (DC). Tuzgen et al reported a series of 6 patients( 4 MCA and 2 ACoA) with malignant vasospasm and proven intracranial hypertension treated with DC, reporting a favorable neurological outcome in $<50 \%$ of the patients (modified Rankin scale $\leq 3) .{ }^{29}$ DC was not indicated because severe ischemic injury made the surgery futile to the attending multidisciplinary team. One patient in our series was treated with therapeutic hypothermia, which produced favorable control of the ICP, but could not prevent cerebral infarction. Other treatment modalities described in the literature are anesthesia of the stellate ganglion, ${ }^{30}$ aortic balloon, ${ }^{31}$ immunosuppressants, ${ }^{32}$ continuous intra-arterial nimodipine, ${ }^{33}$ and ketamine, ${ }^{34}$ but further studies are required. ${ }^{35}$

Limitations of the present study are its small sample size and its retrospective design. In the literature, several series describe outcomes of patients with DCI, but our study is, to our knowledge, the first detailed angiographic description of patients with refractory $\mathrm{DCI}$, reporting other findings besides severe AV, as potential angiographic predictors for further studies. 
Table 2 Angiographic findings

\begin{tabular}{|l|l|l|l|l|l|l|l|l|l|}
\hline Patient & $\begin{array}{l}\text { Clinical } \\
\text { presentation }\end{array}$ & $\begin{array}{l}\text { Timing } \\
\text { to angio- } \\
\text { plasty }\end{array}$ & $\begin{array}{l}\text { AV } \\
\text { severity }\end{array}$ & $\begin{array}{l}\text { Bilateral } \\
\text { AV }\end{array}$ & $\begin{array}{l}\text { Posterior } \\
\text { circulation } \\
\text { AV }\end{array}$ & $\begin{array}{l}\text { Distal } \\
\text { AV }\end{array}$ & $\begin{array}{l}\text { Slow } \\
\text { Circulatory } \\
\text { times }\end{array}$ & $\begin{array}{l}\text { Number } \\
\text { of angio- } \\
\text { plasties }\end{array}$ & $\begin{array}{l}\text { Angioplasty } \\
\text { type }\end{array}$ \\
\hline 1 & $\mathrm{Cl}$ & 9 & Severe & Yes & Yes & Yes & No & 1 & B \\
\hline 2 & $\begin{array}{l}\text { Aphasia, } \\
\text { Hemiparesis }\end{array}$ & 8 & Severe & Yes & No & Yes & Yes & 1 & $\mathrm{~B}$ \\
\hline 3 & $\mathrm{Cl}$ & 7 & Severe & Yes & No & No & No & 1 & $\mathrm{P}$ \\
\hline 4 & $\mathrm{Cl}$ & 8 & Severe & Yes & No & Yes & Yes & 3 & $\mathrm{~B}(1), \mathrm{P}(2)$ \\
\hline 5 & $\mathrm{Cl}$ & 6 & $\begin{array}{l}\text { Moder- } \\
\text { ate }\end{array}$ & No & No & No & Yes & 2 & $\mathrm{P}(2)$ \\
\hline 6 & $\mathrm{Cl}$ & 4 & Mild & Yes & No & Yes & No & 1 & $\mathrm{P}$ \\
\hline 7 & $\mathrm{Cl}$ & 8 & Severe & Yes & Yes & Yes & No & 1 \\
\hline
\end{tabular}

Abbreviation: AV, angiographic vasospasm; B, balloon angioplasty; $\mathrm{Cl}$, consciousness impairment; P, pharmacological angioplasty.

\section{Conclusion}

Common angiographic findings in refractory DCI were severe vessel stenosis, slow circulatory times, distal cortical stenosis, and bilateral circulatory compromise. More studies are needed to establish an association between individual angiographic findings and clinical outcome in SAH patients.

\section{Source of Funding}

None.

\section{Disclosure}

None.

\section{Conflicts of Interests}

The authors have no conflicts of interests to declare

\section{References}

1 Macdonald RL. Delayed neurological deterioration after subarachnoid haemorrhage. Nat Rev Neurol 2014;10(01):44-58

2 Weidauer S, Lanfermann H, Raabe A, Zanella F, Seifert V, Beck J. Impairment of cerebral perfusion and infarct patterns attributable to vasospasm after aneurysmal subarachnoid hemorrhage: a prospective MRI and DSA study. Stroke 2007;38(06):1831-1836

3 Crowley RW, Medel R, Dumont AS, et al. Angiographic vasospasm is strongly correlated with cerebral infarction after subarachnoid hemorrhage. Stroke 2011;42(04):919-923

4 Rijsdijk M, van der Schaaf IC, Velthuis BK, Wermer MJ, Rinkel GJ. Global and focal cerebral perfusion after aneurysmal subarachnoid hemorrhage in relation with delayed cerebral ischemia. Neuroradiology 2008;50(09):813-820

5 Aralasmak A, Akyuz M, Ozkaynak C, Sindel T, Tuncer R. CT angiography and perfusion imaging in patients with subarachnoid hemorrhage: correlation of vasospasm to perfusion abnormality. Neuroradiology 2009;51(02):85-93

6 Rosalind Lai PM, Du R. Role of Genetic Polymorphisms in Predicting Delayed Cerebral Ischemia and Radiographic Vasospasm After Aneurysmal Subarachnoid Hemorrhage: A Meta-Analysis. World Neurosurg 2015;84(04):933-41.e2

7 Brown RJ, Kumar A, Dhar R, Sampson TR, Diringer MN. The relationship between delayed infarcts and angiographic vasospasm after aneurysmal subarachnoid hemorrhage. Neurosurgery 2013;72(05):702-707, discussion 707-708
8 Naraoka M, Matsuda N, Shimamura N, Asano K, Ohkuma H. The role of arterioles and the microcirculation in the development of vasospasm after aneurysmal SAH. BioMed Res Int 2014; 2014:253746

9 Frontera JA, Fernandez A, Schmidt JM, et al. Defining vasospasm after subarachnoid hemorrhage: what is the most clinically relevant definition? Stroke 2009;40(06):1963-1968

10 Claassen J, Bernardini GL, Kreiter K, et al. Effect of cisternal and ventricular blood on risk of delayed cerebral ischemia after subarachnoid hemorrhage: the Fisher scale revisited. Stroke 2001;32(09):2012-2020

11 Report of World Federation of Neurological Surgeons Committee on a Universal Subarachnoid Hemorrhage Grading Scale. J Neurosurg 1988;68(06):985-986

12 Mura J, Rojas-Zalazar D, Ruíz A, Vintimilla LC, Marengo JJ. Improved outcome in high-grade aneurysmal subarachnoid hemorrhage by enhancement of endogenous clearance of cisternal blood clots: a prospective study that demonstrates the role of lamina terminalis fenestration combined with modern microsurgical cisternal blood evacuation. Minim Invasive Neurosurg 2007;50(06):355-362

13 Komotar RJ, Olivi A, Rigamonti D, Tamargo RJ. Microsurgical fenestration of the lamina terminalis reduces the incidence of shunt-dependent hydrocephalus after aneurysmal subarachnoid hemorrhage. Neurosurgery 2002;51(06):1403-1412, discussion 1412-1413

14 Dorhout Mees SM, Rinkel GJ, Feigin VL, et al. Calcium antagonists for aneurysmal subarachnoid haemorrhage. Cochrane Database Syst Rev 2007;(03):CD000277

15 Kumar G, Shahripour RB, Harrigan MR. Vasospasm on transcranial Doppler is predictive of delayed cerebral ischemia in aneurysmal subarachnoid hemorrhage: a systematic review and meta-analysis. J Neurosurg 2016;124(05):1257-1264

16 Diringer MN, Bleck TP, Claude Hemphill J III, et al; Neurocritical Care Society. Critical care management of patients following aneurysmal subarachnoid hemorrhage: recommendations from the Neurocritical Care Society's Multidisciplinary Consensus Conference. Neurocrit Care 2011;15(02):211-240

17 Connolly ES Jr, Rabinstein AA, Carhuapoma JR, et al; American Heart Association Stroke Council; Council on Cardiovascular Radiology and Intervention; Council on Cardiovascular Nursing; Council on Cardiovascular Surgery and Anesthesia; Council on Clinical Cardiology. Guidelines for the management of aneurysmal subarachnoid hemorrhage: a guideline for healthcare professionals from the American Heart Association/american Stroke Association. Stroke 2012;43(06): $1711-1737$ 
18 Dankbaar JW, Rijsdijk M, van der Schaaf IC, Velthuis BK, Wermer MJ, Rinkel GJ. Relationship between vasospasm, cerebral perfusion, and delayed cerebral ischemia after aneurysmal subarachnoid hemorrhage. Neuroradiology 2009;51(12):813-819

19 Lanterna LA, Lunghi A, Martchenko S, Gritti P, Bonaldi G, Biroli F. Cerebral watershed hypoperfusion in subarachnoid hemorrhage: computed tomography perfusion analysis. J Neurosurg 2011;114 (04):961-968

20 Mortimer AM, Steinfort B, Faulder K, Harrington T. Delayed infarction following aneurysmal subarachnoid hemorrhage: Can the role of severe angiographic vasospasm really be dismissed? J Neurointerv Surg 2016;8(08):802-807

21 Qureshi AI, Sung GY, Suri MA, Straw RN, Guterman LR, Hopkins LN. Prognostic value and determinants of ultraearly angiographic vasospasm after aneurysmal subarachnoid hemorrhage. Neurosurgery 1999;44(05):967-973, discussion 973-974

22 Al-Mufti F, Roh D, Lahiri S, et al. Ultra-early angiographic vasospasm associated with delayed cerebral ischemia and infarction following aneurysmal subarachnoid hemorrhage. J Neurosurg 2017;126(05):1545-1551

23 Phan K, Moore JM, Griessenauer CJ, et al. Ultra-Early Angiographic Vasospasm After Aneurysmal Subarachnoid Hemorrhage: A Systematic Review and Meta-Analysis. World Neurosurg 2017; 102:632-638.e1

24 Abla AA, Wilson DA, Williamson RW, et al. The relationship between ruptured aneurysm location, subarachnoid hemorrhage clot thickness, and incidence of radiographic or symptomatic vasospasm in patients enrolled in a prospective randomized controlled trial. J Neurosurg 2014;120(02):391-397

25 Dabus G, Nogueira RG. Current options for the management of aneurysmal subarachnoid hemorrhage-induced cerebral vasospasm: a comprehensive review of the literature. Intervent Neurol 2013;2(01):30-51

26 Pandey AS, Elias AE, Chaudhary N, Thompson BG, Gemmete JJ. Endovascular treatment of cerebral vasospasm: vasodilators and angioplasty. Neuroimaging Clin N Am 2013;23(04):593-604
27 Bauer AM, Rasmussen PA. Treatment of intracranial vasospasm following subarachnoid hemorrhage. Front Neurol 2014;5:72

28 Hollingworth M, Chen PR, Goddard AJ, Coulthard A, Söderman M, Bulsara KR. Results of an International Survey on the Investigation and Endovascular Management of Cerebral Vasospasm and Delayed Cerebral Ischemia. World Neurosurg 2015;83(06): 1120-1126.e1

29 Tuzgen S, Kucukyuruk B, Aydin S, Ozlen F, Kizilkilic O, Abuzayed B. Decompressive craniectomy in patients with cerebral infarction due to malignant vasospasm after aneurysmal subarachnoid hemorrhage. J Neurosci Rural Pract 2012;3(03): 251-255

30 Jain V, Rath GP, Dash HH, Bithal PK, Chouhan RS, Suri A. Stellate ganglion block for treatment of cerebral vasospasm in patients with aneurysmal subarachnoid hemorrhage - A preliminary study. J Anaesthesiol Clin Pharmacol 2011;27 (04):516-521

31 Lylyk P, Vila JF, Miranda C, Ferrario A, Romero R, Cohen JE. Partial aortic obstruction improves cerebral perfusion and clinical symptoms in patients with symptomatic vasospasm. Neurol Res 2005; 27(Suppl 1):S129-S135

32 Pradilla G, Chaichana KL, Hoang S, Huang J, Tamargo RJ. Inflammation and cerebral vasospasm after subarachnoid hemorrhage. Neurosurg Clin N Am 2010;21(02):365-379

33 Hockel K, Diedler J, Steiner J, et al. Long-Term, Continuous IntraArterial Nimodipine Treatment of Severe Vasospasm After Aneurysmal Subarachnoid Hemorrhage. World Neurosurg 2016; 88:104-112

34 Von der Brelie C, Seifert M, Rot S, et al. Sedation of Patients with Acute Aneurysmal Subarachnoid Hemorrhage with Ketamine Is Safe and Might Influence the Occurrence of Cerebral Infarctions Associated with Delayed Cerebral Ischemia. World Neurosurg 2017;97:374-382

35 Durrant JC, Hinson HE. Rescue therapy for refractory vasospasm after subarachnoid hemorrhage. Curr Neurol Neurosci Rep 2015; 15(02):521 